\title{
Estudos Anatômicos de Folhas de Plantas Daninhas. I - Nicandra physaloides, Solanum viarum, Solanum americanum E Raphanus raphanistrum ${ }^{1}$
}

\author{
Anatomical Studies of Weed Leaves. I - Nicandra physaloides, Solanum viarum, Solanum \\ americanum and Raphanus raphanistrum
}

FERREIRA, E.A. ${ }^{2}$, PROCÓPIO, S.O. ${ }^{3}$, SILVA, E.A.M. ${ }^{4}$, SILVA, A.A. ${ }^{5}$ e RUFINO, R.J.N. ${ }^{2}$

RESUMO - O objetivo deste trabalho foi estudar a anatomia das folhas das espécies de plantas daninhas Nicandra physaloides (joá-de-capote), Solanum viarum (joá-bravo), Solanum americanum (maria-pretinha) e Raphanus raphanistrum (nabiça), visando obter melhor entendimento sobre as barreiras que cada espécie impõe à penetração dos herbicidas. Folhas completamente expandidas do terceiro ao quinto nó foram coletadas de plantas de ocorrência espontânea no campo. Das folhas de cada espécie foram obtidas três amostras da região central mediana, com aproximadamente $1 \mathrm{~cm}^{2}$, as quais foram utilizadas em estudos da estrutura, clarificação e nas observações em microscópio eletrônico de varredura (MEV). Todas as espécies avaliadas são anfiestomáticas. O principal obstáculo foliar à penetração de herbicidas constatado em N. physaloides foi a alta densidade tricomática. Já em relação a S. viarum, baixa densidade estomática na face adaxial, alta densidade tricomática, presença de placas de cera epicuticular e grande espessura das cutículas foram as principais barreiras detectadas. S. americanum apresentou como principais obstáculos foliares à penetração de herbicidas a baixa densidade estomática na face adaxial e a grande espessura da cutícula da face adaxial, sendo esta última a única barreira constatada nas folhas de $R$. raphanistrum.

Palavras-chave: cutícula, cera epicuticular, estômato, tricoma, feixes vasculares.

\begin{abstract}
This research aimed to study the leaf anatomy of the weed species Nicandra physaloides, Solanum viarum, Solanum americanum and Raphanus raphanistrum to acquire a better understanding of the barriers each species imposes upon herbicide penetration. Completely expanded leaves from the third to the fifth node were collected from plants spontaneously occurring in field. Three samples, with approximately $1 \mathrm{~cm}^{2}$, were taken at the central portion of the leaves in each species. These samples were used in structural studies, clarification and observation using a scanning-electron microscope (SEM). All species are amphistomatic. The main leaf barrier against herbicide penetration in $\mathbf{N}$. physaloides was high trichomic density, whereas in $\mathbf{S}$. viarum, the main barriers were low stomatic density in the adaxial side, high trichomic density, high content of epicuticular wax and high cuticle thickness. S. americanum's main leaf barriers were low stomatic density and high cuticle thickness in the adaxial side. High cuticle thickness in the adaxial side was the only barrier observed in leaves of $\boldsymbol{R}$. raphanistrum.
\end{abstract}

Key words: cuticle, epicuticular wax, stomata, trichome, vascular bunches.

Recebido para publicação em 22/4/2002 e na forma revisada em 7/8/2002.

2 Acadêmico de Agronomia, estagiário do Dep. de Biologia Vegetal da Universidade Federal de Viçosa - UFV, 36571-000 Viçosa-MG, <ealves.ferreira@bol.com.br>; ${ }^{3}$ Doutorando em Fitotecnia, UFV, <procopio@alunos.ufv.br.>; ${ }^{4}$ Prof. do Dep. de Biologia Vegetal da UFV, <esilva @ mail.ufv.br>; ${ }^{5}$ Prof. do Dep. de Fitotecnia da UFV, <aasilva@ mail.ufv.br>; ${ }^{2}$ Acadêmico de Agronomia, estagiário do Dep. de Biologia Vegetal da UFV, <rufino@homenet.com.br>. 


\section{INTRODUÇÃO}

A penetração dos herbicidas através dos tecidos vegetais é fundamental para a eficiência do produto no controle de plantas daninhas. Os herbicidas podem penetrar nas plantas pelas suas estruturas aéreas (folhas, caules, flores e frutos) e subterrâneas (raízes, rizomas, estolões, tubérculos, etc.), pelas sementes e também, durante a germinação e emergência, pela radícula e pelo caulículo (Silva et al., 2000). Contudo, são as folhas o principal órgão das plantas daninhas envolvido na penetração de herbicidas aplicados em pós-emergência.

A morfologia das plantas, principalmente das folhas, influencia a quantidade do herbicida interceptado e retido; entretanto, é a anatomia destas que praticamente determina a facilidade com que esses produtos serão absorvidos.

Em superficies foliares que possuem pouco desenvolvimento de cera epicuticular (ex.: Beta vulgaris), as gotas da calda herbicida pulverizada cobrem grandes áreas, produzindo vários depósitos nas depressões acima das paredes anticlinais. Quando o herbicida é aplicado do mesmo modo sobre folhas com altos niveis de cera epicuticular (ex.: Cynodon dactylon), os depósitos formados são menores, ocasionando menor porcentagem da superfície foliar coberta com o herbicida e, assim, reduzindo o número de células onde a absorção poderia ocorrer (Hess \& Falk, 1990).

As folhas das plantas apresentam vários níveis de desenvolvimento de tricomas e glândulas. Abutilon theophrasti, por exemplo, possui tricomas simples e complexos. Chenopodium album possui alta densidade de tricomas glandulares na epiderme adaxial, que pode deixar as células da epiderme propriamente ditas totalmente escondidas (Hess \& Falk, 1990). Tricomas presentes na superfície foliar podem interceptar gotas pulverizadas, impedindo que estas alcancem a epiderme. Mesmo quando os tricomas são simples e aparecem em baixa densidade, ocorre a aderência de gotas sobre eles. A eficiência da absorção de herbicidas pelos tricomas e a translocação destes para as células epidérmicas ainda são parcialmente desconhecidas (Hess \& Falk, 1990). No entanto, de acordo com Hull (1970), alguma absorção de determinadas substâncias pode ocorrer via tricomas. Todavia, poucos autores afirmam ser os tricomas bom caminho para a entrada de herbicidas. Hess \& Falk (1990), fazendo revisão de literatura, encontraram na maioria dos trabalhos que existe uma relação negativa entre a aderência dos herbicidas nos tricomas e a eficácia desses produtos.

A cutícula é a principal via de absorção dos herbicidas aplicados em pós-emergência, sendo o seu conhecimento de importância fundamental nos estudos de absorção. O uso de surfatantes siliconados tem contribuído para a quebra da tensão superficial da calda de pulverização na folha, ocasionando assim maior espalhamento do produto e permitindo que os estômatos passem a ter também importante papel na penetração dos herbicidas. Segundo Audus (1976), a tensão superficial máxima para que ocorra boa penetração da calda de aplicação nos estômatos é de 30 dinas $\mathrm{cm}^{-1}$. Outro fator ligado à penetração dos herbicidas pelos estômatos é que a cutícula sobre as células-guarda parece ser mais fina e mais permeável (menor teor de cera epicuticular) a substâncias do que a cutícula sobre outras células epidérmicas (Hess \& Falk, 1990).

Segundo Hess \& Falk (1990), a maioria das plantas daninhas apresenta em suas folhas estômatos sobre as superficies adaxial e abaxial (anfiestomáticas). No entanto, Silva et al. (2000) e Velini \& Trindade (1992) relatam que, na maioria dessas plantas, os estômatos se localizam na face abaxial das folhas (hipoestomáticas). Meyer et al. (1973), realizando contagens do número de estômatos de 39 espécies, observaram que 16 eram anfiestomáticas e as 23 restantes, hipoestomáticas. Também acrescentam que, nas anfiestomáticas, o número de estômatos na face adaxial era normalmente inferior ao da face abaxial. É importante lembrar que, em pulverizações agrícolas, a dificuldade de as gotículas atingirem a face abaxial é grande; conseqüentemente, a importância da absorção pelos estômatos desta face é tida como reduzida. Outro fator que leva os pesquisadores a acreditarem na pouca importância da absorção de herbicidas através dos estômatos é o fato de estes, em vários horários do dia, se encontrarem fechados, inclusive em aplicações noturnas. Contudo, Taylor et al. (1980) observaram em seus estudos que os estômatos foram a principal via de penetração 
do herbicida bentazon em folhas de Chenopodium album.

A cutícula recobre todas as células da epiderme da planta e serve como interface entre o corpo da planta e o ambiente, realizando a proteção e a prevenção da perda de água dos tecidos vegetais (Bukovac et al., 1990). A cutícula é também importante barreira à entrada de microrganismos e agroquímicos, inclusive de herbicidas. Herbicidas que diferem em estrutura e polaridade atravessam com maior ou menor dificuldade a cutícula. O mecanismo exato de penetração ainda não é conhecido para todos os produtos, mas admite-se que os compostos não-polares sigam a rota lipofílica e os compostos polares, a rota hidrofílica (Silva et al., 2000). De acordo com os mesmos autores, supõe-se que os herbicidas lipofilicos se solubilizam nos componentes lipofílicos da cutícula e se difundem através desta. Já em relação aos herbicidas hidrofilicos, admite-se que a cutícula tenha estrutura porosa, que se mantém hidratada, dependendo das condições ambientais, sendo essa água de hidratação da cutícula a rota de penetração destes herbicidas. Outra possivel rota de absorção dos herbicidas polares, citada por Velini \& Trindade (1992), é através dos filamentos de pectina, que podem cruzar praticamente toda a cutícula e, desde que hidratados, atuar como via de transporte desses produtos.

Nicandra physaloides apresenta folhas alternas ou geminadas, com limbo membranáceo, liso, de formato geralmente ovalado, com base rapidamente atenuada e ápice agudo e margens sinuado-lobadas a dentadas, de formato irregular (Kissmann, 1999). As folhas de Solanum viarum são simples, alternas, e as superiores podem ser geminadas, de limbo largamente ovalado, com base subcordada e margens sinuado-lobadas, com ápice agudo ou acuminado (Kissmann, 1999). Solanum americanum possui folhas simples, alternas, de limbo membranáceo, ovalado ou rômbico, com base atenuada e ápice agudo e margem sinuada ou angulada (Kissmann, 1999). A morfologia das folhas de Raphanus raphanistrum é extremamente variável: as folhas inferiores são fortemente lobadas, havendo um lobo terminal maior e vários lobos laterais, e as divisões entre eles são geralmente profundas, atingindo a nervura mediana; já as folhas superiores são normalmente menos lobadas e menores (Kissmann, 1999).

O objetivo deste trabalho foi analisar a estrutura foliar de quatro espécies de plantas daninhas de grande ocorrência no Brasil, visando obter melhor entendimento sobre as barreiras que cada espécie impõe à penetração dos herbicidas e, assim, fornecer subsídios à busca de estratégias para superar esses obstáculos.

\section{MATERIAL E MÉTODOS}

As plantas daninhas avaliadas foram Nicandra physaloides (joá-de-capote), Solanum viarum (joá-bravo), Solanum americanum (maria-pretinha) e Raphanus raphanistrum (nabiça). A divisão das espécies por família se encontra na Tabela 1.

Tabela 1 - Espécies vegetais e famílias estudadas. ViçosaMG, 2002

\begin{tabular}{|l|l|}
\hline \multicolumn{1}{|c|}{ Espécie vegetal } & Família \\
\hline Nicandra physaloides & Solanaceae \\
Solanum viarum & Solanaceae \\
Solanum americanum & Solanaceae \\
Raphanus raphanistrum & Cruciferae \\
\hline
\end{tabular}

As folhas das plantas daninhas foram coletadas de três plantas de ocorrência espontânea no campo. De cada espécie vegetal foi coletada uma folha do terceiro ao quinto nó, quando elas estavam completamente expandidas. As folhas foram coletadas, armazenadas diretamente em FAA 50 e transportadas ao Laboratório de Anatomia Vegetal do Departamento de Biologia Vegetal da Universidade Federal de Viçosa.

De cada folha, de cada espécie, foram obtidas três amostras da região central mediana, com aproximadamente $1 \mathrm{~cm}^{2}$, as quais foram utilizadas para: a) estudos da organização estrutural, b) clarificação e c) observações em microscópio eletrônico de varredura (MEV).

\section{a) Estudo da composição estrutural da folha}

As amostras foram fixadas, durante 24 horas em vácuo, em mistura de álcool etílico $70 \%$, ácido acético e formol (FAA 70), na proporção de 9:0,5:0,5, respectivamente. Após 
a fixação, foram desidratadas em uma série etílica-butílica progressiva, embebidas em parafina histológica (PF $48-54{ }^{\circ} \mathrm{C}$ ) e emblocadas em mistura de parafina histológica e cera na proporção de 8:1 v/v. Seções de 10 a $13 \mu \mathrm{m}$ foram obtidas com um micrótomo rotativo Ultracut - Leica RM-2155 e montadas em lâminas histológicas. Depois da desparafinização, os cortes foram corados com fuccina básica e azul-de-astra e montados em bálsamo-docanadá. Foram preparadas lâminas de cortes transversais a fresco, que foram submetidas ao reagente citoquímico Sudam III, para caracterização das cutículas. Após seleção, alguns cortes foram fotomicrografados, com auxílio de um fotomicroscópio Olympus AX 70 equipado com acessório fotográfico U-PHOTO (Olympus), e analisados pelo software IMAGE PRO-PLUS. Foram determinadas as seguintes espessuras: lâmina foliar, epidermes superior e inferior, parênquimas (paliçádico, lacunoso, homogêneo) e cutícula (adaxial e abaxial). Avaliou-se também o nível de vascularização foliar das espécies vegetais.

\section{b) Clarificação}

As amostras foram clarificadas em álcool etílico a $70 \%$ e branqueadas com solução de $\mathrm{NaOH}$ a $5 \%$ e em hipoclorito de sódio durante dois a três minutos. Depois dessa etapa, as amostras foram lavadas e desidratadas em uma série etílica progressiva, coradas com safranina ( $1 \%$ solução aquosa) e azul-de-astra e montadas em bálsamo-do-canadá (Berlyn \& Mikshe, 1976, modificado). Fotomicrografias das epidermes superior e inferior foram feitas em fotomicroscópio Olympus AX 70.

Dessas lâminas foram obtidos o índice estomático, a densidade estomática, o comprimento do ostíolo e a densidade de tricomas nas superfícies adaxial e abaxial de cada espécie observada. O índice estomático foi calculado pela razão entre o número de estômatos e o número total de células da epiderme (número de estômatos + células epidérmicas) x 100 .

\section{c) Observações ao Microscópio Eletrônico de Varredura (MEV)}

Parte das amostras das folhas foram fixadas em glutaraldeído a 6\% na temperatura de $4{ }^{\circ} \mathrm{C}$ durante 24 horas, pós-fixadas em tetróxido de ósmio a 3\% na mesma temperatura durante duas horas, lavadas em solução-tampão de cacodilato de sódio e desidratadas em série alcoólica progressiva até álcool etílico absoluto. Essas amostras foram submetidas ao ponto crítico de dessecamento de $\mathrm{CO}_{2}$ em equipamento CPD 020 Ballers Union, montadas em suportes metálicos e cobertas com ouro paládio (Bozzola \& Russel, 1992). O material foliar preparado foi observado e eletromicrografado em microscópio eletrônico de varredura JEOL T-200.

\section{RESULTADOS E DISCUSSÃO}

\section{Nicandra physaloides}

Esta espécie apresenta lâmina foliar com espessura média de 146,55 $\mu \mathrm{m}$ (Tabela 2 e Figura 1). As epidermes são simples, sendo a adaxial mais espessa que a abaxial (Tabela 2). Seu mesofilo foliar é dorsiventral, pouco compacto; o parênquima paliçádico apresenta uma camada de células com espessura média de 55,93 $\mu \mathrm{m}$, e a espessura média do parênquima lacunoso é de 79,22 um (Tabela 2 e Figura 1). As folhas são anfiestomáticas (Figuras 2 e 3), e nas duas faces os estômatos estão dispostos no mesmo nivel das demais células da epiderme. Tanto na face adaxial quanto na abaxial os estômatos são anomocíticos, porém os da face abaxial são maiores

Tabela 2 - Espessura de componentes foliares das espécies de plantas daninhas estudadas. Viçosa-MG, 2002

\begin{tabular}{|l|c|c|c|c|c|c|c|}
\hline \multirow{2}{*}{ Espécie vegetal } & Lâmina foliar & $\begin{array}{c}\text { Epiderme } \\
\text { adaxial }\end{array}$ & $\begin{array}{c}\text { Epiderme } \\
\text { abaxial }\end{array}$ & $\begin{array}{c}\text { Parênquima } \\
\text { paliçádico }\end{array}$ & $\begin{array}{c}\text { Parênquima } \\
\text { lacunoso }\end{array}$ & $\begin{array}{c}\text { Parênquima } \\
\text { homogêneo }\end{array}$ \\
\cline { 2 - 7 } & \multicolumn{7}{|c|}{ Espessura $(\mu \mathrm{m})$} \\
\hline Nicandra physaloides & 146,55 & 11,45 & 10,42 & 55,93 & 79,22 & - \\
Solanum viarum & 127,71 & 12,48 & 9,44 & 48,53 & 49,06 & - \\
Solanum americanum & 247,54 & 19,81 & 9,92 & 95,13 & 106,40 & - \\
Raphanus raphanistrum & 217,28 & 15,42 & 13,49 & 61,95 & 126,23 & - \\
\hline
\end{tabular}


(Tabela 3). Foi verificada maior presença de estômatos na face abaxial das folhas (Tabela 3). Tricomas tectores e glandulares multicelulares não-ramificados foram observados em ambas as faces das folhas (Tabela 4). A cutícula é mais espessa na face adaxial das folhas (Tabela 4). Sua taxa de vascularização foliar média é de três feixes a cada $590 \mu \mathrm{m}$ de largura foliar (Tabela 4).

\section{Solanum viarum}

Apresenta lâmina foliar com espessura média de 127,71 um (Tabela 2 e Figura 1). As epidermes são simples, porém a adaxial é mais espessa que a abaxial (Tabela 2). Seu mesofilo foliar é dorsiventral; o parênquima paliçádico apresenta uma camada de células com espessura média de $48,53 \mu \mathrm{m}$, e a espessura média do parênquima lacunoso é de 49,06 $\mu \mathrm{m}$ (Tabela 2 e Figura 1). As folhas são anfiestomáticas; na face adaxial os estômatos estão dispostos na mesma linha da epiderme e na face abaxial estes se encontram projetados pouco acima do nível das demais células da epiderme. Tanto na face adaxial quanto na abaxial os estômatos são anomocíticos, entretanto os da face abaxial são pouco maiores
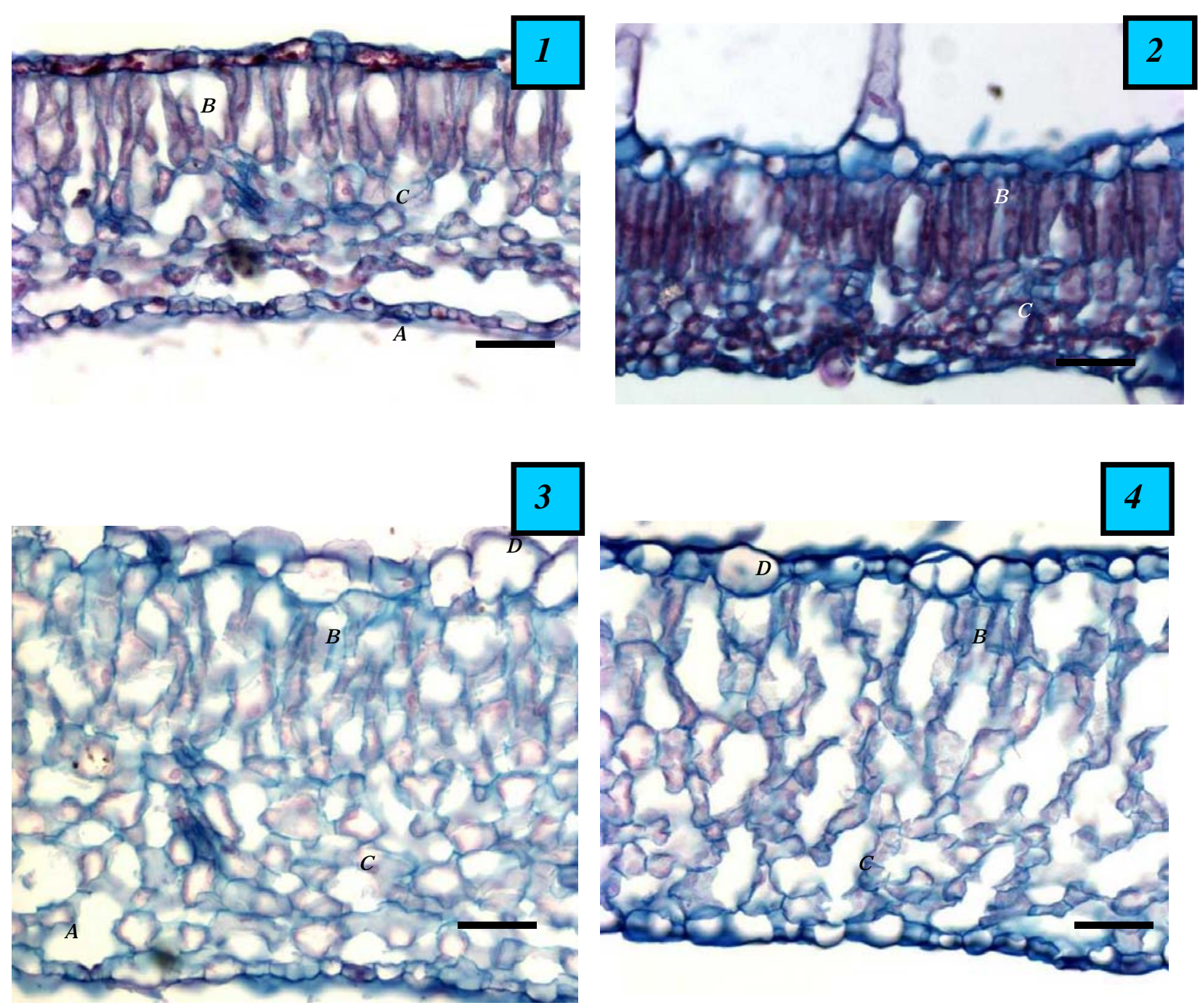

Figura 1 - Seção transversal das folhas de: 1. joá-de-capote (Nicandra physaloides), 2. joá-bravo (Solanum viarum), 3. mariapretinha (Solanum americanum) e 4. nabiça (Raphanus raphanistrum). A: estômato na epiderme abaxial, B: parênquima paliçádico, C: parênquima lacunoso e D: epiderme adaxial. (Barra $=50 \mu \mathrm{m})$. Microscopia fotônica $(\mathrm{MF})$. 
(Tabela 3). Foi verificada maior presença de estômatos na face abaxial das folhas, sendo esta a espécie, entre as demais avaliadas, que apresentou a menor presença de estômatos na face adaxial (Tabela 3 e Figuras 4 e 5). Três tipos de tricomas foram observados em suas folhas: tricomas tectores multicelulares não-ramificados, tricomas tectores unicelulares não-ramificados e tricomas glandulares multicelulares

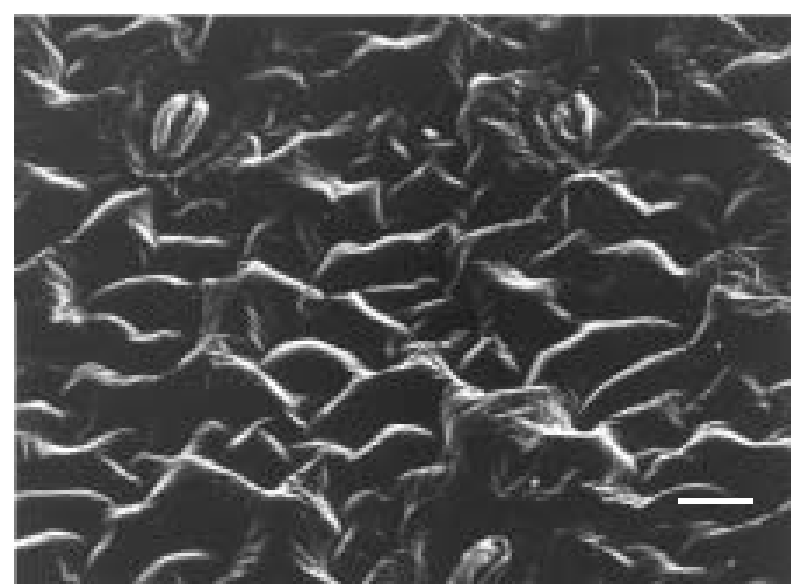

Figura 2 - Superfície foliar da face abaxial de Nicandra physaloides utilizando Microscopia Eletrônica de Varredura $(\mathrm{MEV})$. $($ Barra $=10 \mu \mathrm{m})$. não-ramificados nas duas faces das folhas (Tabela 4 e Figuras 1 e 5). A cutícula é mais espessa na face adaxial das folhas (Tabela 4) e apresenta placas de cera esporádicas (Figura 4). Sua taxa de vascularização foliar média é de sete feixes a cada $590 \mu \mathrm{m}$ de largura foliar (Tabela 4). Constatou-se a ocorrência de areia cristalificada em idioblastos no parênquima lacunoso entre os feixes vasculares.

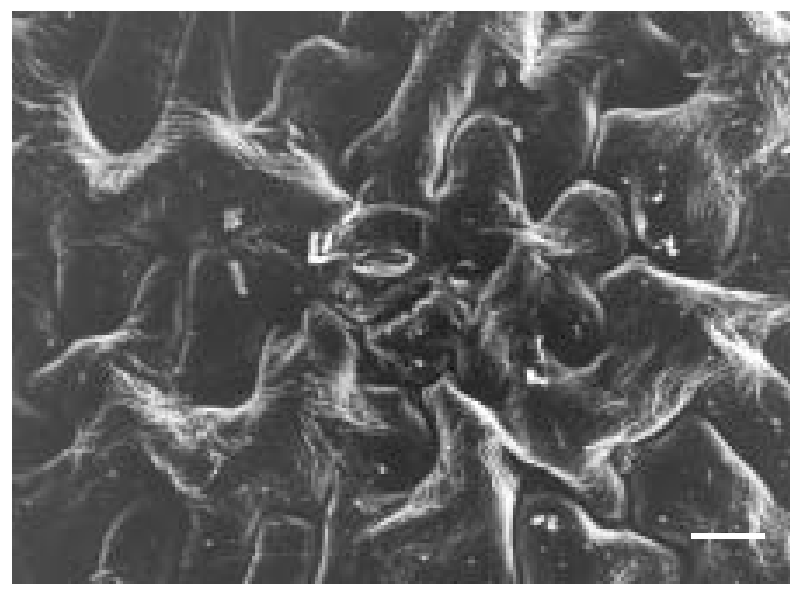

Figura 3 - Superfície foliar da face adaxial de Nicandra physaloides $(\mathrm{MEV})$. $($ Barra $=10 \mu \mathrm{m})$.

Tabela 3 - Índice estomático, densidade estomática e comprimento de ostíolos das espécies de plantas daninhas estudadas. Viçosa-MG, 2002

\begin{tabular}{|l|c|c|c|c|c|c|}
\hline \multirow{2}{*}{\multicolumn{1}{|c|}{ Espécie vegetal }} & \multicolumn{2}{|c|}{ Índice estomático $(\%)$} & \multicolumn{2}{c|}{$\begin{array}{c}\text { Densidade estomática } \\
\left(\text { estômatos } \mathrm{mm}^{-2}\right)\end{array}$} & \multicolumn{2}{c|}{$\begin{array}{c}\text { Comprimento do ostíolo } \\
(\mu \mathrm{m})\end{array}$} \\
\cline { 2 - 7 } & adaxial & abaxial & adaxial & abaxial & adaxial & abaxial \\
\hline Nicandra physaloides & 12,97 & 27,62 & 98 & 233 & 14,98 & 17,23 \\
Solanum viarum & 4,21 & 21,28 & 16 & 132 & 14,14 & 15,68 \\
Solanum americanum & 4,44 & 28,66 & 27 & 242 & 14,05 & 11,00 \\
Raphanus raphanistrum & 24,39 & 31,70 & 236 & 251 & 14,00 & 13,02 \\
\hline
\end{tabular}

Tabela 4 - Espessura de cutícula, densidade tricomática e vascularização de folhas das espécies de plantas daninhas estudadas. Viçosa-MG, 2002

\begin{tabular}{|l|c|c|c|c|c|}
\hline \multirow{2}{*}{ Espécie vegetal } & \multicolumn{2}{|c|}{$\begin{array}{c}\text { Cutícula espessura } \\
(\mu \mathrm{m})\end{array}$} & \multicolumn{2}{c|}{$\begin{array}{c}\text { Densidade tricomática } \\
\left.\text { (tricomas } \mathrm{mm}^{-2}\right)\end{array}$} & $\begin{array}{c}\text { Número de feixes } \\
\text { vasculares em } 590 \mu \mathrm{m} \\
\text { de lâmina foliar }\end{array}$ \\
\cline { 2 - 5 } & adaxial & abaxial & adaxial & abaxial & 3 \\
Nicandra physaloides & 1,11 & 0,86 & 5,20 & 4,00 & 7 \\
Solanum viarum & 2,14 & 1,85 & 4,80 & 10,40 & 3 \\
Solanum americanum & 2,31 & 1,16 & 1,60 & - & 1 \\
Raphanus raphanistrum & 1,66 & 1,22 & 1,00 & - & 3 \\
\hline
\end{tabular}




\section{Solanum americanum}

Esta espécie apresenta lâmina foliar com espessura média de 247,54 um (Tabela 2 e Figura 1). As epidermes são simples, com a epiderme adaxial apresentando aproximadamente o dobro da espessura da epiderme abaxial (Tabela 2). Seu mesofilo foliar é dorsiventral, pouco compacto; o parênquima paliçádico apresenta duas camadas de células com espessura total média de 95,13 $\mu$ m, e a espessura média do parênquima lacunoso é de 106,40 $\mu \mathrm{m}$ (Tabela 2 e Figura 1). As folhas são anfiestomáticas (Figuras 6 e 7), e em ambas as faces os estômatos estão dispostos no mesmo

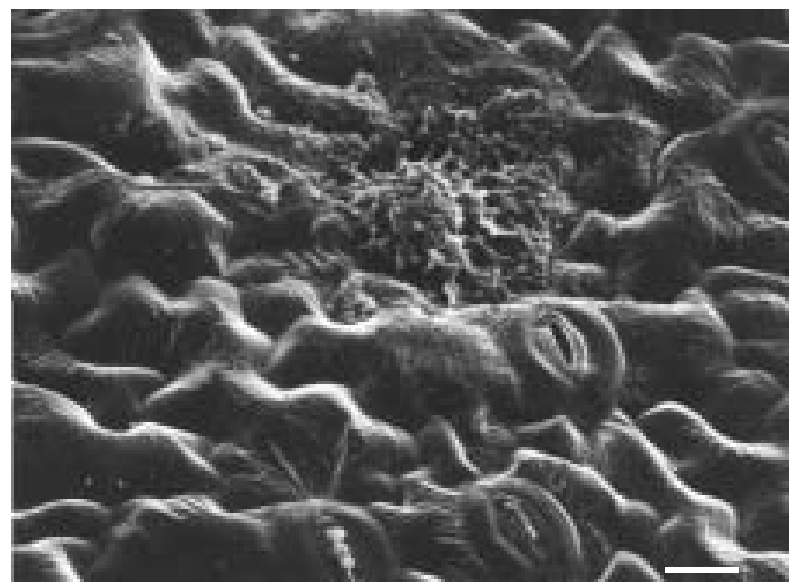

Figura 4 - Superfície foliar da face abaxial de Solanum viarum $(\mathrm{MEV})$. $($ Barra $=10 \mu \mathrm{m})$.

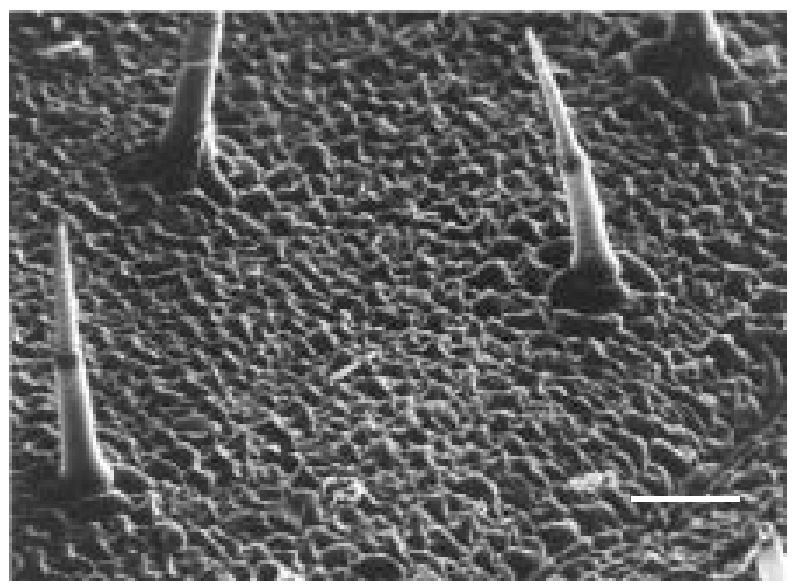

Figura 5 - Superfície foliar da face adaxial de Solanum viarum $(\mathrm{MEV}) .($ Barra $=100 \mu \mathrm{m})$. nível das demais células epidérmicas. Tanto na face adaxial quanto na abaxial os estômatos são anomocíticos, e os da face adaxial são maiores (Tabela 3). Foi verificada maior presença de estômatos na face abaxial das folhas (Tabela 3). Tricomas glandulares multicelulares não-ramificados foram observados ao longo das nervuras na face abaxial das folhas. Também foi constatada a ocorrência de tricomas tectores multicelulares não-ramificados na face adaxial (Tabela 4). A cutícula é mais espessa na face adaxial das folhas (Tabela 4). Sua taxa de vascularização foliar média é de três feixes a cada $590 \mu \mathrm{m}$ de largura foliar (Tabela 4).

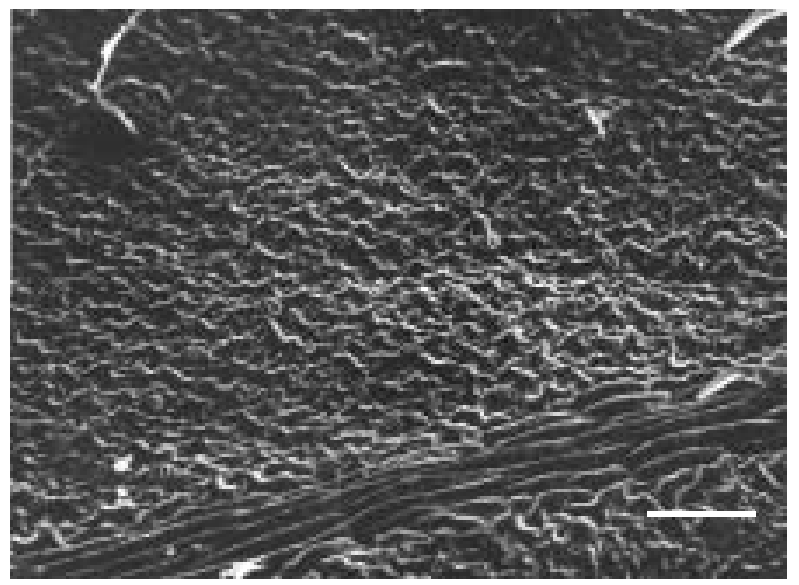

Figura 6 - Superfície foliar da face abaxial de Solanum americanum $(\mathrm{MEV})$. (Barra $=100 \mu \mathrm{m})$.

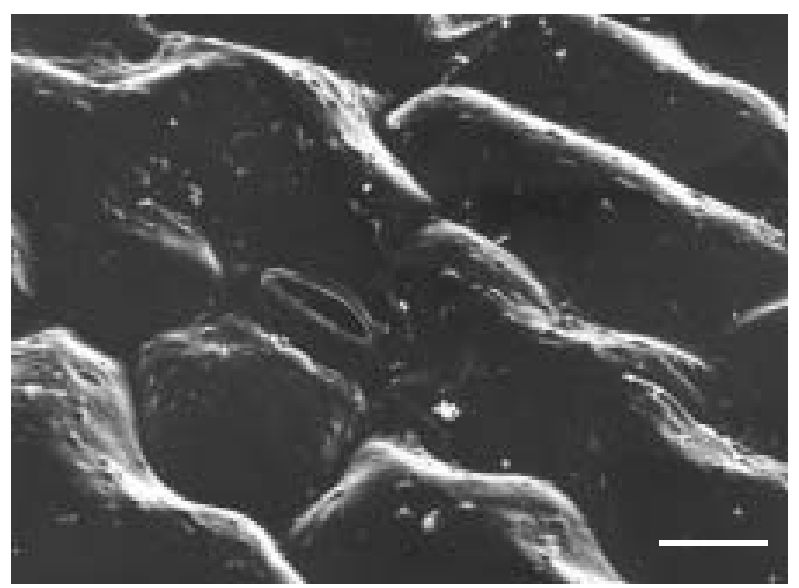

Figura 7 - Superfície foliar da face adaxial de Solanum americanum $(\mathrm{MEV})$. (Barra $=10 \mu \mathrm{m})$.

Planta Daninha, Viçosa-MG, n.2, p.159-167, 2002 


\section{Raphanus raphanistrum}

Esta espécie apresenta lâmina foliar com espessura média de 217,28 $\mu \mathrm{m}$ (Tabela 2 e Figura 1). As epidermes são simples, sendo a adaxial pouco mais espessa que a abaxial (Tabela 2). Seu mesofilo foliar é dorsiventral, pouco compacto, o parênquima paliçádico apresenta uma camada de células com espessura média de $61,95 \mu \mathrm{m}$, e a espessura média do parênquima lacunoso é de 126,23 $\mu \mathrm{m}$ (Tabela 2 e Figura 1). As folhas são anfiestomáticas (Figuras 8 e 9), e nas duas faces os estômatos estão dispostos no mesmo nível das demais células epidérmicas e apresentam grandes câmaras subestomáticas. Tanto na face adaxial quanto na abaxial os estômatos são anisocíticos, sendo os da face adaxial pouco maiores (Tabela 3). Foi verificada maior presença de estômatos na face abaxial das folhas, porém essa diferença foi pequena (Tabela 3). Tricomas tectores unicelulares não-ramificados foram observados na face adaxial das folhas (Tabela 4). A cutícula é mais espessa na face adaxial das folhas (Tabela 4). Sua taxa de vascularização foliar média é de um feixe a cada $590 \mu \mathrm{m}$ de largura foliar (Tabela 4).

O resumo das principais barreiras foliares à penetração dos herbicidas presentes nas espécies de plantas daninhas avaliadas é apresentado na Tabela 5. O principal obstáculo foliar à penetração de herbicidas constatado na planta daninha $N$. physaloides foi a alta densidade tricomática. Já em relação a S. viarum,

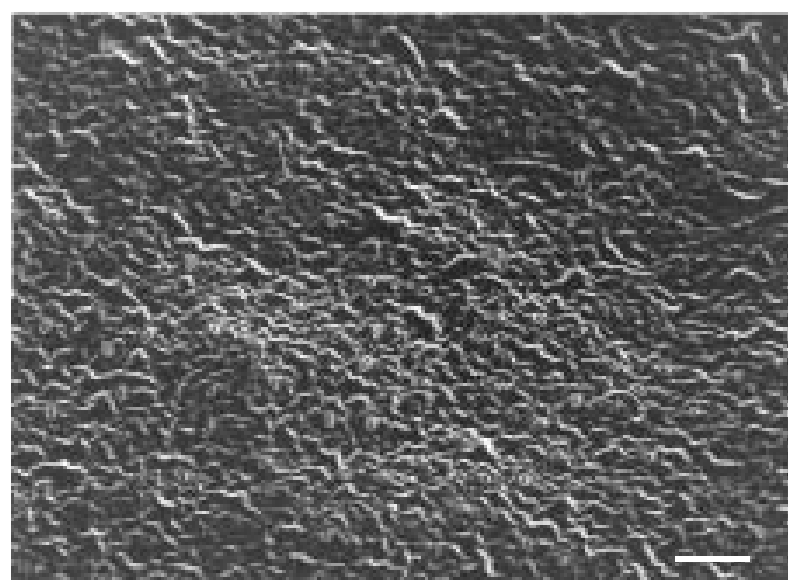

Figura 8 - Superfície foliar da face abaxial de Raphanus raphanistrum $(\mathrm{MEV})$. (Barra $=100 \mu \mathrm{m})$.

Planta Daninha, Viçosa-MG, v.20, n.2, p.159-167, 2002 baixa densidade estomática na face adaxial, alta densidade tricomática, presença de placas de cera epicuticular e grande espessura das cutículas foram as principais barreiras detectadas. S. americanum apresentou como principais obstáculos foliares à penetração de herbicidas a baixa densidade estomática na face adaxial e a grande espessura da cutícula da face adaxial. A grande espessura da cutícula da face adaxial foi a única barreira constatada nas folhas de $R$. raphanistrum.

Com base nas características anatômicas das folhas de $N$. physaloides e $R$. raphanistrum, o uso de surfatantes organossiliconados que aumentam a penetração estomática pode ser uma estratégia interessante, devido à relativa alta densidade estomática apresentada por essas

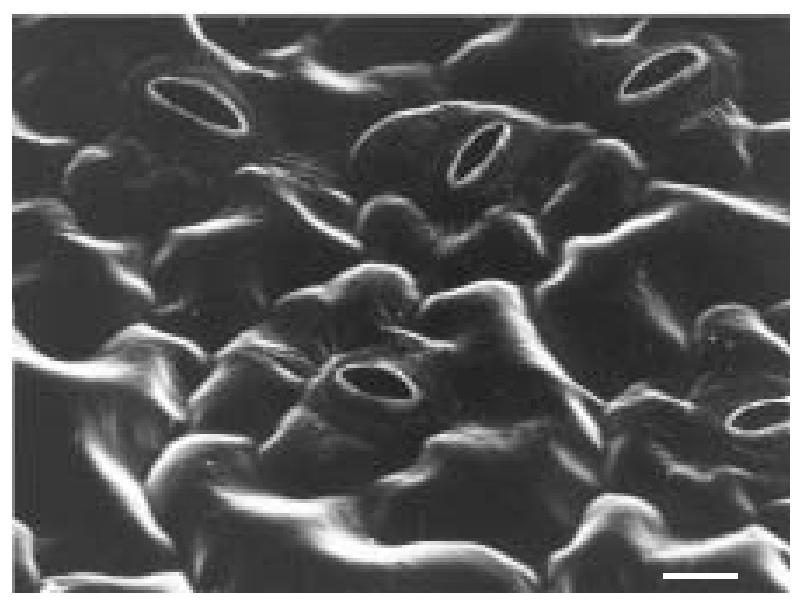

Figura 9 - Superfície foliar da face adaxial de Raphanus raphanistrum $(\mathrm{MEV})$. (Barra $=10 \mu \mathrm{m})$.

Tabela 5 - Principais barreiras à penetração de herbicidas em folhas das espécies de plantas daninhas estudadas. Viçosa-MG, 2002

\begin{tabular}{|l|l|}
\hline \multicolumn{1}{|c|}{ Espécie vegetal } & \multicolumn{1}{|c|}{$\begin{array}{c}\text { Principais barreiras foliares à } \\
\text { penetração de herbicidas }\end{array}$} \\
\hline Nicandra physaloides & Alta densidade tricomática \\
\hline Solanum viarum & $\begin{array}{l}\text { Baixa densidade estomática na face } \\
\text { adaxial; alta densidade tricomática; } \\
\text { presença de placas de cera } \\
\text { epicuticular; grande espessura das } \\
\text { cutículas }\end{array}$ \\
\hline Solanum americanum & $\begin{array}{l}\text { Baixa densidade estomática na face } \\
\text { adaxial; grande espessura da cutícula } \\
\text { da face adaxial }\end{array}$ \\
\hline Raphanus raphanistrum & $\begin{array}{l}\text { Grande espessura da cutícula da face } \\
\text { adaxial }\end{array}$ \\
\hline
\end{tabular}


espécies e, também, ao grande comprimento dos ostíolos dos estômatos de N. physaloides, o que facilita a quebra da tensão superficial da calda herbicida. Com relação a S. viarum, a hidratação das placas de cera epicuticular, por exemplo, por meio de irrigação antes da aplicação do herbicida, e o uso de óleos minerais ou vegetais na calda de aplicação podem facilitar a absorção dos herbicidas. Técnicas de aplicação que facilitem o molhamento da face abaxial das folhas de $S$. americanum, como regulagem da pressão do pulverizador, escolha da ponta de pulverização e uso de surfatantes organossiliconados, podem proporcionar maior penetração dos herbicidas, pois esta face, nesta espécie, apresenta menor espessura de cutícula e maior densidade estomática.

\section{LITERATURA CITADA}

AUDUS, L. J. The physiology and biochemistry of herbicides. 2.ed. New York: 1976. 467 p.

BERLYN, G. P; MIKSHE, J. P. Botanical microtechnique and cytochemistry. Ames: The Iowa State University Press, 1976. 325 p.

BOZZOLA, J. J.; RUSSELL, L. D. Electron microscopy. Boston: Jones and Bartlett Publishers, 1992. 542 p.
BUKOVAC, M. J. et al. Sorption of organic compounds by plant cuticles. Weed Sci., v. 38, n. 3, p. 289-298, 1990.

HESS, F. D.; FALK, R. H. Herbicide deposition on leaf surfaces. Weed Sci., v. 38, n. 3, p. 280-288, 1990.

HULL, H. M. Leaf structure as related to absorption of pesticides and other compounds. Residue Rev., v. 31, p. 1-155, 1970.

KISSMANN, K. G. Plantas infestantes e nocivas. 2.ed. São Paulo: 1999. t. 2. 976 p.

MEYER, B. et al. Introdução à fisiologia vegetal. 2.ed. Lisboa: 1973.710 p.

SILVA, A. A. et al. Controle de plantas daninhas. Brasília, DF: ABEAS, 2000. 260 p.

TAYLOR, F. E.; COBB, A. H.; DAVIES, L. G. The effects of bentazon on stomatal behavior in Chenopodium album $\mathrm{L}$. New Phytologist, v. 63, p. 369-376, 1980.

VELINI, E. D.; TRINDADE, M. L. B. Comportamento de herbicidas na planta. Épocas de aplicação de herbicidas. In: SIMPÓSIO NACIONAL SOBRE MANEJO INTEGRADO DE PLANTAS DANINHAS EM HORTALIÇAS, 1992, Botucatu, SP. Anais... Botucatu: UNESP, 1992. p. 65-86. 